\title{
Antral Follicles Count and Anti-Müllerian Hormone Levels after Gonadotoxic Chemotherapy in Patients with Breast Cancer: Cohort Study
}

\section{Contagem de folículos antrais e níveis de hormônio anti- Mülleriano após quimioterapia gonadotóxica em pacientes com câncer de mama: estudo de coorte}

Ângela Marcon D’Avila ${ }^{1}$ Edison Capp ${ }^{1,2}$ Helena von Eye Corleta ${ }^{1,2,3}$

\begin{abstract}
Address for correspondence Edison Capp, MD, Prof., Serviço de Ginecologia e Obstetrícia, Hospital de Clínicas de Porto Alegre UFRGS, Rua Ramiro Barcelos, 2350/11 ${ }^{\circ}$ andar, Porto Alegre, RS, CEP 90035-903, Brazil (e-mail: edcapp@ufrgs.br).
\end{abstract}

\author{
Abstract \\ Keywords \\ - anti-Müllerian \\ hormone \\ - antral follicle count \\ - ovarian reserve \\ - chemotherapy- \\ induced amenorrhea \\ - anovulation
}

Aim To assess ovarian reserve (OVR) by means of follicle-stimulating hormone (FSH), anti-Müllerian hormone (AMH), and antral follicle count (AFC) measurement in eumenorrheic women with breast cancer, exposed to gonadotoxic chemotherapy. Method Fifty-two women ( $35.3 \pm 3.8$ years old) with breast cancer and undergoing cyclophosphamide-containing chemotherapy were enrolled. The assessment was performed before chemotherapy (T1) and after 2 (T2) and 6 months (T3).

Results Six months after chemotherapy, the prevalence of regular cycles was $60 \%$. Anti-Müllerian hormone decreased down to undetectable levels at T2 and T3 (T1: 2.53 [1.00-5.31]; T2 < 0.08; T3: $<0.08[<0.08-1.07] \mathrm{ng} / \mathrm{mL}),(p<0.0001)$. Antral follicle count was 11 [8.0-13.5] follicles at T1 and lower at T2 (5.50 [3.75-8.0] and T3 (5.0 [2.5-7.0]) $(p<0.0001)$. In patients who remained with regular cycles during chemotherapy or resumed normal menses, FSH and estradiol levels remained unchanged. Conclusion Anti-Müllerian hormone and AFC are useful as markers of OVR decline in women exposed to chemotherapy. Follicle-stimulating hormone is only adequate in women who become amenorrheic. received July 22, 2016 accepted after revision January 16, 2017 published online April 11, 2017
DOI http://dx.doi.org/ 10.1055/s-0037-1601438. ISSN 0100-7203.
Copyright $\odot 2017$ by Thieme-Revinter

Publicações Ltda, Rio de Janeiro, Brazil
License terms

(c) $(1) \$$ 
Resumo

Palavras-chave

- hormônio antiMülleriano

- contagem de folículos antrais

- reserva ovariana

- amenorreia induzida por quimioterapia

- anovulação
Objetivo Avaliar a reserva ovariana (OVR) através da contagem de folículos antrais (AFC), dosagem sérica de hormônio folículo estimulante (FSH) e hormônio antiMülleriano (AMH) em mulheres com câncer de mama submetidas a quimioterapia gonadotóxica.

Método Foram incluídas na pesquisa 52 mulheres (35,3 \pm 3,8 anos) com câncer de mama, em tratamento com quimioterapia com ciclofosfamida. As dosagens e medidas foram realizadas antes do início da quimioterapia (T1) e após 2 (T2) e 6 meses (T3).

Resultados Seis meses após quimioterapia, a prevalência de ciclos regulares foi de $60 \%$. O AMH sérico diminuiu a níveis indetectáveis em T2 e T3 (T1: 2,53 [1,00-5,31] ]; $\mathrm{T} 2<0,08 ; \mathrm{T} 3:<0,08[<0,08-1,07] \mathrm{ng} / \mathrm{mL})(p<0,0001)$. A contagem de folículos antrais foi de 11 [8,0-13,5] folículos em T1, e ainda menor em T2 $(5,50$ [3,75-8,0] e T3 $(5,0[2,5-7,0]),(p<0,0001)$. Em pacientes que mantiveram ciclos regulares durante a quimioterapia ou retomaram a menstruação normalmente, os níveis de FSH e estradiol permaneceram inalterados.

Conclusão $\mathrm{O}$ AMH e a AFC são marcadores úteis do declínio da OVR em mulheres expostas à quimioterapia. O FSH só é adequado em mulheres que se tornam amenorreicas.

\section{Introduction}

Ovarian reserve (OVR) is the measure used to assess the capacity of the ovary to produce oocytes. It can be inferred from serum levels of follicle-stimulating hormone (FSH), inhibin $\mathrm{B}$, and anti-Müllerian hormone (AMH), as well as by the antral follicle count (AFC), which is the number of follicles $2-10 \mathrm{~mm}$ in size as assessed by transvaginal ultrasonography during the first phase of the cycle. Low OVR reflects ovarian "aging" and jeopardizes reproductive potential. ${ }^{1,2}$

A systematic review of the literature assessing several markers of OVR in the assisted reproductive technology setting was published in 2006. ${ }^{2}$ Levels of estradiol, the first marker assessed, were not shown to be effective predictors of OVR-related outcomes, even when combined with other markers. ${ }^{3}$ Follicle-stimulating hormone measurements are affected only when OVR is critically jeopardized. ${ }^{4,5}$ In a 2002 study of potential predictors of poor response to ovarian stimulation for in vitro fertilization (IVF) cycles, Bancsi et al $^{3}$ showed that AFC alone provided the best prognostic value as compared with FSH, inhibin B, and estradiol.

More recently, AMH has been considered the best available marker of OVR, particularly as its levels do not vary over the course of the menstrual cycle, and become undetectable after menopause. ${ }^{6-9}$ Anti-Müllerian hormone is a dimeric glycoprotein produced by granulosa cells from the 3rd month of intrauterine life. Its production increases in puberty, and it is believed to exert autocrine and paracrine effects during follicle development. It modulates the primordial to primary follicle transition by inhibiting granulosa cell proliferation, aromatase activity, and luteinizing hormone (LH) receptor expression., ${ }^{70-13}$

In the 1950s, investigators found that women exposed to chemotherapy (CTX) developed premature ovarian failure. ${ }^{14}$ This effect was later attributed to the gonadotoxicity of chemotherapeutic agents and found even in patients who resumed regular menses after CTX. ${ }^{15,16}$ The main mechanism underlying CTX-induced anovulation, particularly in women treated with alkylating agents, are follicular depletion by apoptosis with loss of germ cells (oocytes), steroidogenic theca and granulosa cells. ${ }^{17}$

This study sought to assess OVR by means of AMH measurement in eumenorrheic women with breast cancer, exposed to gonadotoxic CTX. Other OVR markers (FSH and AFC) were compared with AMH in an attempt to ascertain which one is most sensitive for measurement of the decline in OVR after CTX.

\section{Methods}

\section{Design}

Cohort study.

\section{Patients}

The study sample comprised women with a diagnosis of breast cancer and indications for cyclophosphamide-containing CTX. From July of 2007 to November of 2009, 52 women aged 40 years or younger, with regular menses and no prior history of CTX (inclusion criteria), were recruited from six hospitals in Brazil. Previous ovarian surgery was an exclusion criterion. The study protocol (\#07-061) was approved by the corresponding Research Ethics Committees and was conducted in accordance with the Brazilian guidelines and standards for human subject research.

Assessments were performed at baseline before the start of the CTX cycles (T1) and then at 2 (T2) and 6 months (T3) after completion of therapy. Each assessment consisted of an interview, blood sample collection for hormone measurement, and gynecologic ultrasonography for AFC quantification. The number of CTX cycles (4 or 6 ) and the dose of chemotherapeutic agent by total body surface area were also collected. 


\section{Anti-Müllerian Hormone Measurement}

Blood samples were centrifuged at $3500 \mathrm{rpm}$ for 15 minutes and the supernatant serum stored at $-80^{\circ} \mathrm{C}$ for later analysis. Follicle-stimulating hormone and estradiol were measured by chemiluminescence performed with Siemens ADVIA CentaurXP Immunoassay System (Munich, Germany). Anti-Müllerian hormone was measured with a commercially available enzyme-linked immunosorbent assay (ELISA) kit made by Beckman Coulter - Immunotech (Marseille, France), as described by Long et al. ${ }^{18}$

\section{Ultrasonography}

All sonograms were performed by the same examiner using the Sonoline Adara system by Siemens (Munich, Germany) and a $5 \mathrm{MHz}$ transvaginal transducer. In view of the urgency of instituting CTX, ultrasonography was performed on any day of the menstrual cycle. Determination of the AFC took into account follicles with a mean diameter of 2-10 $\mathrm{mm}^{19-21}$

\section{Statistics}

The sample size required to detect a $1.4 \mathrm{ng} / \mathrm{mL}$ difference in AMH levels from baseline until 6 months after CTX, with a significance level of 0.05 , and a statistical power of $90 \%$, was 44 patients. Calculation was based on the findings of van Rooij et al. ${ }^{9}$

Data processing and analysis were performed in the SPSS 18 software (SPSS Inc., Chicago, IL, USA) environment. Data were asymmetrically distributed and are thus expressed as medians. The following tests were used: Mann-Whitney U test and Kruskal-Wallis test for independent samples; Friedman test for related samples, and Wilcoxon test for comparisons. The significance level was set at $p>0.05$.

\section{Results}

The mean age of the patients was $35.3 \pm 3.8$ years (range, 27-40 years). Ductal invasive carcinoma was the most common histologic tumor type (51/98\%) and there was one case of Paget disease (1/2\%). Most cases were treated by breastconserving surgery with adjuvant $(31 / 60 \%)$ or neoadjuvant (21/41\%) CTX and $75 \%$ of the patients received local radiotherapy. The mean length of follow-up was $14 \pm 3$ months.

Over the course of the study, five patients were lost to follow-up (three were unable to keep appointments due to disease recurrence, one discontinued treatment, and one died). Complete follow-up was obtained from 49 patients in $\mathrm{T} 2$ and 47 in $\mathrm{T} 3$.

During CTX, $40 \%$ of the women developed irregular cycles (amenorrhea or oligomenorrhea); 2 months after completion of CTX (4 to 6 cycles of cyclophosphamide), $85 \%$ of the patients were irregular. At 6 months post-CTX, 60\% of the patients remained with irregular menses or amenorrheic, whereas $40 \%$ had resumed normal menses.

- Table 1 shows changes in the evaluated markers of OVR before and after CTX. Baseline assessment of OVR before CTX yielded values within the expected range for women of reproductive age ( $\mathbf{- T a b l e ~} \mathbf{2}$ ).

Table 1 Markers of OVR before chemotherapy (T1), at 2 (T2) and at 6 months (T3) after completion of chemotherapy. Data expressed as median [interquartile range]. The limit of detection for $\mathrm{AMH}$ was $0.08 \mathrm{ng} / \mathrm{mL}$

\begin{tabular}{|l|l|l|l|}
\hline Marker & $\begin{array}{l}\text { T1 } \\
\boldsymbol{n}=52\end{array}$ & $\begin{array}{l}\text { T2 } \\
\boldsymbol{n}=49\end{array}$ & $\begin{array}{l}\text { T3 } \\
\boldsymbol{n}=57\end{array}$ \\
\hline Estradiol $(\mathrm{pg} / \mathrm{mL})$ & $79.42(48.22-149)$ & $27.55(8.47-108.85)$ & $95.50(29.37-310.85)$ \\
\hline FSH $(\mathrm{IU} / \mathrm{mL})$ & $6.71(3.87-8.64)^{\mathrm{a}, \mathrm{b}}$ & $47.67(32.51-88.01)^{\mathrm{a}, \mathrm{c}}$ & $16.31(7.41-41.16)^{\mathrm{b}, \mathrm{c}}$ \\
\hline AMH $(\mathrm{ng} / \mathrm{mL})$ & $2.53(1.0-5.31)^{\mathrm{a}, \mathrm{b}}$ & $<0.08^{\mathrm{a}, \mathrm{d}}$ & $<0.08(<0.08-1.07)^{\mathrm{b}}$ \\
\hline AFC & $11.0(8-13.5)^{\mathrm{a}, \mathrm{b}}$ & $5.50(3.75-8.0)^{\mathrm{a}}$ & $5.0(2.5-7.0)^{\mathrm{b}}$ \\
\hline
\end{tabular}

${ }^{\mathrm{a}} \mathrm{T} 1$ versus $\mathrm{T} 2 ; p<0.05$

'T1 versus T3; $p<0.05$.

${ }^{\mathrm{C}} \mathrm{T} 2$ versus $\mathrm{T} 3 ; p<0.05$.

${ }^{\mathrm{d}}$ There is no variation because all patients had values below the detection limit.

Abbreviations: AFC, antral follicle count; AMH, anti-Müllerian hormone; FSH, follicle-stimulating hormone; OVR, ovarian reserve.

Table 2 Markers of OVR 6 months after chemotherapy (T3), stratified by menstrual status. Data expressed as median [interquartile range]

\begin{tabular}{|l|l|l|l|}
\hline & $\begin{array}{l}\text { Eumenorrhea } \\
(40 \%)\end{array}$ & $\begin{array}{l}\text { Oligo/amenorrhea } \\
(60 \%)\end{array}$ & $p$ \\
\hline Estradiol $(\mathrm{pg} / \mathrm{mL})$ & $\begin{array}{l}146.9(70.1-515.6) \\
\text { AMH }(\mathrm{ng} / \mathrm{mL})\end{array}$ & $\begin{array}{l}54.9(9.87-302.9) \\
<0.08\end{array}$ & $\begin{array}{l}0.032 \\
<0.0001\end{array}$ \\
\hline FSH $(\mathrm{IU} / \mathrm{mL})$ & $7.24(3.87-14)$ & $34.91(15.7-52.65)$ & $<0.0001$ \\
\hline AFC & $7.0(5.5-10.0)$ & $3.5(2.0-6.0)$ & $<0.001$ \\
\hline
\end{tabular}

Abbreviations: AFC, antral follicle count; AMH, anti-Müllerian hormone; FSH, follicle-stimulating hormone; OVR, ovarian reserve. 
There were no significant differences in estradiol levels at any of the time points of the assessment. Follicle-stimulating hormone was 6.71 [3.87-8.64] $\mathrm{IU} / \mathrm{mL}$ at $\mathrm{T} 1$, significantly higher at T2 (47.67 [32.51-88.01] IU/mL), and significantly lower at T3 (16.31 [7.41-41.16] IU/mL), $(p<0.001)$. AntiMüllerian hormone levels declined significantly between T1 (2.53 [1-5.31] ng/mL) and T2 (undetectable), with $p<0.0001$. Six months after CTX (T3), AMH levels the same as in T2 $(p=0.128)$, even though some patients had resumed normal menses. The median AFC at T1 was 11 [813.5] follicles, significantly higher than at T2 and T3 $(p<0.0001)$. There were no significant differences between AFCs at T2 (5.5 [3.75-8]) and T3 (5 [2.5-7]) (-Table 1).

- Table 2 shows the levels of OVR markers in eumenorrheic and oligo/amenorrheic patients (40 and $60 \%$ of the sample respectively) at 6 months post-CTX (T3). There were statistically significant differences in estradiol, FSH, AMH levels, as well as in AFCs. Median estradiol in the eumenorrhea group was 146.9 [70.1-515.6] pg/mL versus 54.9 [9.87302.9] $\mathrm{pg} / \mathrm{mL}$ in the oligo/amenorrheic group $(p=0,032)$. Median FSH in the eumenorrhea group was 7.24 [3.87-14] $\mathrm{IU} / \mathrm{mL}$ versus 34.91 [15.71-52.65] IU $/ \mathrm{mL}$ in the anovulatory group ( $p<0.0001$ ). Median AMH levels were $1.46 \mathrm{ng} / \mathrm{mL}$ (range, undetectable-4.31) in the eumenorrheic patients, whereas all oligo/amenorrheic women had levels below the threshold of detection ( $p<0.0001)$. Antral follicle counts also differed between the groups, with a median of 7 [5.5-10] follicles in patients who had resumed normal menses versus $3.5[2-6]$ in oligo/anovulatory patients $(p=0.001)$ (-Table 2).

Assessment of patients who remained eumenorrheic at T3 and comparison by pre-CTX OVR markers showed that AMH and AFC declined significantly, despite normal ovulation. In these patients, FSH and estradiol remained unchanged from baseline (-Table $\mathbf{3}$ ).

At $\mathrm{T} 1$, there were significant negative correlations between AMH and age $(r=-0.523, p<0.0001)$ and between AFC and age $(r=-0.469, p<0.001)$. Antral follicle count and $\mathrm{AMH}$ were positively correlated at T1 and T3 only (-Fig. 1).

Assessment of OVR markers was not influenced by the number of CTX cycles ( 4 or 6 ), nor by the dose of chemotherapeutic agent by total body surface area $\left(\mathrm{mg} / \mathrm{m}^{2}\right.$ ), (data not shown). There was no difference in OVR markers between women who received adjuvant radiation therapy and those who did not.

\section{Discussion}

This study assessed the impact of chemotherapeutic agents on OVR in 52 young women with breast cancer. From a clinical standpoint, CTX exerts rapid and major impact on ovarian function, as $60 \%$ of the patients had become oligo/ anovulatory by the end of the study. These findings are comparable to those of Stearns et $\mathrm{al}^{22}$, who reported amenorrhea as a common event in women exposed to CTX, although it is transient in $50 \%$ of cases. Goodwin et $\mathrm{al}^{23}$ assessed women with breast cancer exposed to cyclophosphamide-containing CTX before the age of 40 and found that $40 \%$ of them became permanently amenorrheic. ${ }^{24}$ Nevertheless, even patients who continue to have normal menses are not spared the negative effects of CTX on ovarian function. ${ }^{25}$ In young patients, assessment of reproductive prognosis after cancer therapy required determination of OVR by reliable markers. In our study, higher AMH and AFC after CXT was associated with menstrual cyclicity. In a previous study, we have demonstrated that the age of 32 years presented $96 \%$ of sensitivity and $39 \%$ of specificity to predict amenorrhea or oligomenorrhea with receiver operating characteristic area under the curve (ROC AUC) of $0.77 .^{26}$

Partridge et $\mathrm{al}^{27}$ showed that CTX-induced damage to ovarian function becomes dose-dependent only after the 6 th treatment cycle; this corroborates our findings, in which no significant differences in OVR or menstrual pattern were observed after four or six CTX cycles with cyclophosphamide.

According to Petrek et $\mathrm{al}^{28}$ the time to resumption of menses in women with transient amenorrhea after CTX does not exceed 15 months. Therefore, assessment of OVR in our study, which was conducted on average 14 months after diagnosis and treatment of breast cancer, should accurately reflect OVR after CTX.

As shown elsewhere in the literature, estradiol was not a good marker of OVR. ${ }^{2,3}$ Follicle-stimulating hormone levels followed the change in the menstrual pattern of the patients at $\mathrm{T} 2$ and $\mathrm{T} 3$, but did not represent the actual decline in reproductive capacity, as oocyte depletion occurs even with normal menses. A reliable marker of OVR should exhibit changes before amenorrhea is established. As FSH reflects these changes too late, as reported by other authors, it is not an adequate marker of OVR. ${ }^{4}$

Anti-Müllerian hormone remained stable at T2 and T3 despite resumption of menstrual cycles in some patients

Table 3 Comparative analysis of OVR markers in eumenorrheic patients before chemotherapy (T1) and 6 months after completion of chemotherapy (T3). Data expressed as median [interquartile range]

\begin{tabular}{|l|l|l|l|}
\hline & T1 & T3 & $p$ \\
\hline FSH $(\mathrm{IU} / \mathrm{mL})$ & $5.03(2.88-7.3)$ & $7.24(3.87-14)$ & 0.125 \\
\hline Estradiol $(\mathrm{pg} / \mathrm{mL})$ & $123.15(49.55-185.12)$ & $146.9(70.1-515.62)$ & 0.96 \\
\hline AFC & $13(11-15.5)$ & $7(5.5-10)$ & 0.001 \\
\hline AMH $(\mathrm{ng} / \mathrm{mL})$ & $6.17(3.19-10.07)$ & $1.46(<0.08-4.31)$ & 0.001 \\
\hline
\end{tabular}

Abbreviations: AFC, antral follicle count; AMH, anti-Müllerian hormone; FSH, follicle-stimulating hormone; OVR, ovarian reserve. 
T1

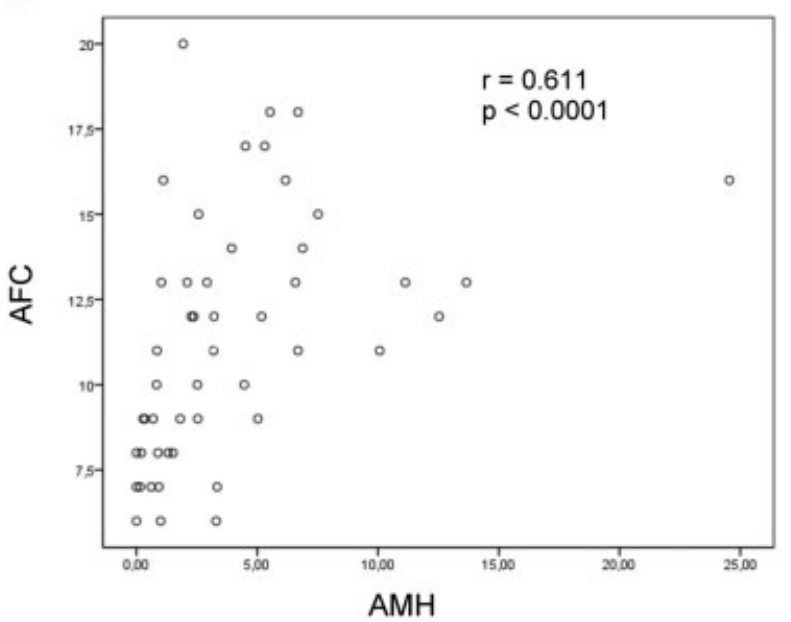

T2

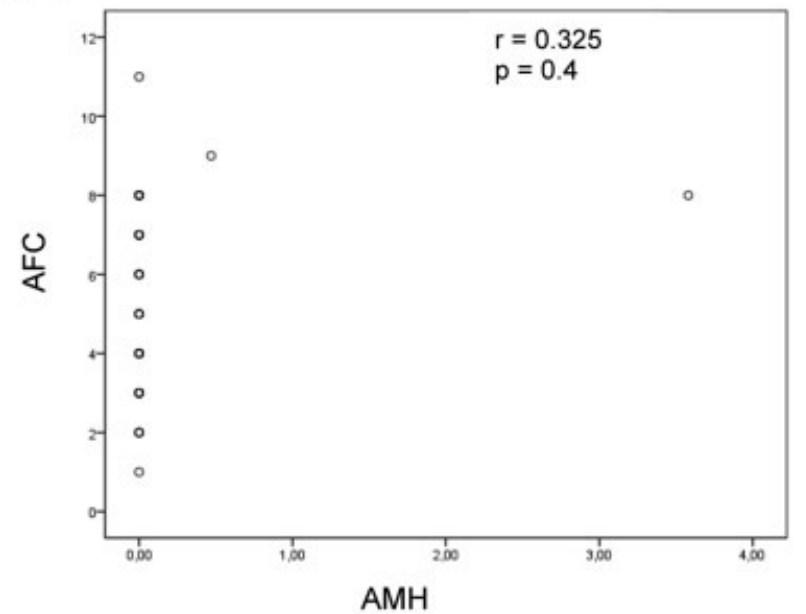

T3

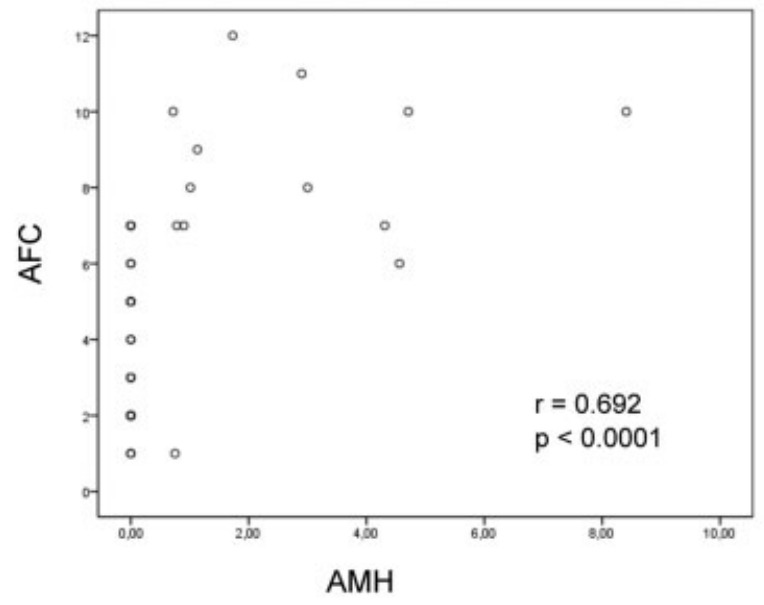

Fig. 1 Correlation between AFC and AMH levels at T1, T2, and T3. Abbreviations: AFC, antral follicle count; $\mathrm{AMH}$, anti-Müllerian hormone.

who were oligo/amenorrheic at $\mathrm{T} 2$, which demonstrates that changes in AMH reflect the true impact of CTX on OVR. As the $\mathrm{AMH}$ is secreted by developing follicles, their depletion after exposure to chemotherapeutic agents leads to a decline in levels of the hormone, even in eumenorrheic patients and, according to some authors, ${ }^{29,30}$ it seems to be of value in assessing ovarian function and advising patients before ${ }^{31}$ and after cancer treatment.

In 2006, Anderson et $\mathrm{al}^{32}$ published the 1 -year results of a cohort of 50 women with breast cancer treated with CTX. Anti-Müllerian hormone was the earliest marker of chemotherapy-induced follicular depletion. Lie Fong et $\mathrm{al}^{33}$ compared AMH levels in a cohort of 185 women with regular menses who had been exposed to CTX before the age of 18 (at least 5 years before the study) to those of 42 control subjects, and found that survivors with lower levels of $\mathrm{AMH}$ were under greater risk of irregular menses and ovarian failure.

Antral follicle counts decrease after CTX and, despite resumption of menstrual cycles in some patients at T3, counts remained unchanged as compared with $\mathrm{T} 2$. These findings suggest that AFC and AMH reflect the gonadotoxicity of chemotherapeutic agents on OVR regardless of menses. These markers demonstrate substantial changes even before clinically apparent menstrual pattern alteration and hence, they can be used to identify significant OVR reduction (whether induced by a gonadotoxic insult or by physiological changes, such as age) in women that are still ovulatory.

Although CTX damages the ovarian stroma and affects oocytes at any stage, it appears to be particularly deleterious to primary follicles and spare resting follicles, which explains the transient anovulation exhibited by some patients at T2. ${ }^{34}$ Patients with a higher primordial follicle count (usually younger ones or those with a better pre-CTX ovarian reserve) still preserve a significant number of these follicles, which, upon development as part of the normal folliculogenesis process, lead to resumption of regular menses at T3. We believe the correlation between AMH and AFC is probably lost at $\mathrm{T} 2$ due to a decline in the number of $\mathrm{AMH}$-producing follicles, which is expected to resume at $\mathrm{T} 3$, once the primordial follicles that remained unaffected at $\mathrm{T} 2$ reach the antral stage and start producing AMH.

As expected, on comparison between anovulatory (amenorrheic or oligomenorrheic) and eumenorrheic patients at T3, all OVR-related parameters showed significant differences. However, this finding does not appear relevant to determination of the optimal marker of OVR because clinical changes were already present.

Comparison of the AMH levels and AFCs of eumenorrheic patients at T3 with their T1 levels clearly showed the sensitivity of these parameters as markers of OVR, as both were decreased despite resumption of normal menses. Similar findings were reported by de Vet et $\mathrm{al}^{35}$, who assessed ovarian aging over time among eumenorrheic patients not exposed to gonadotoxic agents. The authors found that in women whose cycles remained regular, only AMH decreased significantly over time, unlike the other markers assessed. ${ }^{35}$ In a similar study, van Rooij et al ${ }^{9,36}$ concluded that AMH at any age and AFC, FSH and inhibin B in older women, accurately reflect changes in OVR among eumenorrheic women at 4-year follow-up. ${ }^{37}$

Markers that allow early identification of a decline in OVR before clinical changes in the menstrual cycle become 
apparent could help to determine reproductive prognosis. $^{38,39}$ This study shows that, in cases of overt decline in ovarian function induced by a proven gonadotoxic agent, AMH and AFC are efficient markers of OVR. Anti-Müllerian hormone is readily measured in serum, not investigatordependent, and provides more reproducible results, whereas AFC can be assessed immediately on ultrasound by a gynecologist or sonographer.

Declaration of Interest Section

The authors report no conflict of interest.

\section{References}

1 Practice Committee of the American Society for Reproductive Medicine. Testing and interpreting measures of ovarian reserve: a committee opinion. Fertil Steril 2012;98(06):1407-1415

2 Broekmans FJ, Kwee J, Hendriks DJ, Mol BW, Lambalk CB. A systematic review of tests predicting ovarian reserve and IVF outcome. Hum Reprod Update 2006;12(06):685-718

3 Bancsi LF, Broekmans FJ, Eijkemans MJ, de Jong FH, Habbema JD, te Velde ER. Predictors of poor ovarian response in in vitro fertilization: a prospective study comparing basal markers of ovarian reserve. Fertil Steril 2002;77(02):328-336

4 Lambalk CB, van Disseldorp J, de Koning CH, Broekmans FJ. Testing ovarian reserve to predict age at menopause. Maturitas 2009; 63(04):280-291

5 Domingues TS, Rocha AM, Serafini PC. Tests for ovarian reserve: reliability and utility. Curr Opin Obstet Gynecol 2010;22(04): 271-276

6 La Marca A, Pati M, Orvieto R, Stabile G, Carducci Artenisio A, Volpe A. Serum anti-müllerian hormone levels in women with secondary amenorrhea. Fertil Steril 2006;85(05):1547-1549

7 La Marca A, Volpe A. Anti-Müllerian hormone (AMH) in female reproduction: is measurement of circulating AMH a useful tool? Clin Endocrinol (Oxf) 2006;64(06):603-610

8 D'Avila AM, Fracasso GL, Capp E, Brum IS, Corleta HE. Hormônio anti-mülleriano: um marcador mais fidedigno da reserva ovariana? Reprod Clim 2008;23:14-19

9 van Rooij IA, Tonkelaar Id, Broekmans FJ, et al. Anti-müllerian hormone is a promising predictor for the occurrence of the menopausal transition. Menopause 2004;11(6 Pt 1):601-606

10 van Rooij IAJ, Broekmans FJM, te Velde ER, et al. Serum antiMüllerian hormone levels: a novel measure of ovarian reserve. Hum Reprod 2002;17(12):3065-3071

11 Durlinger AL, Gruijters MJ, Kramer P, et al. Anti-Müllerian hormone attenuates the effects of FSH on follicle development in the mouse ovary. Endocrinology 2001;142(11):4891-4899

12 Durlinger AL, Kramer P, Karels B, et al. Control of primordial follicle recruitment by anti-Müllerian hormone in the mouse ovary. Endocrinology 1999;140(12):5789-5796

13 La Marca A, De Leo V, Giulini S, et al. Anti-Mullerian hormone in premenopausal women and after spontaneous or surgically induced menopause. J Soc Gynecol Investig 2005;12(07): 545-548

14 Louis J, Limarzi LR, Best WR. Treatment of chronic granulocytic leukemia with myleran. AMA Arch Intern Med 1956;97(03): 299-308

15 Apperley JF, Reddy N. Mechanism and management of treatmentrelated gonadal failure in recipients of high dose chemoradiotherapy. Blood Rev 1995;9(02):93-116

16 Hudson MM. Reproductive outcomes for survivors of childhood cancer. Obstet Gynecol 2010;116(05):1171-1183
17 Blumenfeld Z. Ovarian rescue/protection from chemotherapeutic agents. J Soc Gynecol Investig 2001;8(1, Suppl Proceedings) S60-S64

18 Long WQ, Ranchin V, Pautier P, et al. Detection of minimal levels of serum anti-Müllerian hormone during follow-up of patients with ovarian granulosa cell tumor by means of a highly sensitive enzyme-linked immunosorbent assay. J Clin Endocrinol Metab 2000;85(02):540-544

19 Frattarelli JL, Levi AJ, Miller BT, Segars JH. A prospective assessment of the predictive value of basal antral follicles in in vitro fertilization cycles. Fertil Steril 2003;80(02):350-355

20 Fanchin R, Schonäuer LM, Righini C, Guibourdenche J, Frydman R, Taieb J. Serum anti-Müllerian hormone is more strongly related to ovarian follicular status than serum inhibin B, estradiol, FSH and LH on day 3. Hum Reprod 2003;18(02):323-327

21 Broekmans FJ, de Ziegler D, Howles CM, Gougeon A, Trew G, Olivennes F. The antral follicle count: practical recommendations for better standardization. Fertil Steril 2010;94(03):1044-1051

22 Stearns V, Schneider B, Henry NL, Hayes DF, Flockhart DA. Breast cancer treatment and ovarian failure: risk factors and emerging genetic determinants. Nat Rev Cancer 2006;6(11):886-893

23 Goodwin PJ, Ennis M, Pritchard KI, Trudeau M, Hood N. Risk of menopause during the first year after breast cancer diagnosis. J Clin Oncol 1999;17(08):2365-2370

24 Shapiro CL, Recht A. Side effects of adjuvant treatment of breast cancer. N Engl J Med 2001;344(26):1997-2008

$25 \mathrm{Su}$ HI, Sammel MD, Green J, et al. Antimullerian hormone and inhibin B are hormone measures of ovarian function in late reproductive-aged breast cancer survivors. Cancer 2010;116(03):592-599

26 D'Avila AM, Biolchi V, Capp E, Corleta Hv. Age, anti-müllerian hormone, antral follicles count to predict amenorrhea or oligomenorrhea after chemotherapy with cyclophosphamide. J Ovarian Res 2015;8:82

27 Partridge A, Gelber S, Gelber RD, Castiglione-Gertsch M, Goldhirsch A, Winer E. Age of menopause among women who remain premenopausal following treatment for early breast cancer: long-term results from International Breast Cancer Study Group Trials V and VI. Eur J Cancer 2007;43(11): 1646-1653

28 Petrek JA, Naughton MJ, Case LD, et al. Incidence, time course, and determinants of menstrual bleeding after breast cancer treatment: a prospective study. J Clin Oncol 2006;24(07):1045-1051

29 Dunlop CE, Anderson RA. Uses of anti-Müllerian hormone (AMH) measurement before and after cancer treatment in women. Maturitas 2015;80(03):245-250

30 Bozza C, Puglisi F, Lambertini M, Osa EO, Manno M, Del Mastro L. Anti-Mullerian hormone: determination of ovarian reserve in early breast cancer patients. Endocr Relat Cancer 2014;21(01): R51-R65

31 Ruddy KJ, O'Neill A, Miller KD, et al. Biomarker prediction of chemotherapy-related amenorrhea in premenopausal women with breast cancer participating in E5103. Breast Cancer Res Treat 2014;144(03):591-597

32 Anderson RA, Themmen AP, Al-Qahtani A, Groome NP, Cameron DA. The effects of chemotherapy and long-term gonadotrophin suppression on the ovarian reserve in premenopausal women with breast cancer. Hum Reprod 2006;21(10): 2583-2592

33 Lie Fong S, Laven JS, Hakvoort-Cammel FG, et al. Assessment of ovarian reserve in adult childhood cancer survivors using antiMüllerian hormone. Hum Reprod 2009;24(04):982-990

34 Ben-Aharon I, Shalgi R. What lies behind chemotherapy-induced ovarian toxicity? Reproduction 2012;144(02):153-163

35 de Vet A, Laven JS, de Jong FH, Themmen AP, Fauser BC. Antimüllerian hormone serum levels: a putative marker for ovarian aging. Fertil Steril 2002;77(02):357-362 
168 Ovarian Reserve and Gonadotoxic Chemotherapy Avila et al.

36 van Rooij IAJ, Broekmans FJM, Scheffer GJ, et al. Serum antimullerian hormone levels best reflect the reproductive decline with age in normal women with proven fertility: a longitudinal study. Fertil Steril 2005;83(04):979-987

37 Di Cosimo S, Alimonti A, Ferretti G, et al. Incidence of chemotherapy-induced amenorrhea depending on the timing of treatment by menstrual cycle phase in women with early breast cancer. Ann Oncol 2004;15(07):1065-1071
38 Barnabei A, Strigari L, Marchetti P, et al. Predicting ovarian activity in women affected by early breast cancer: a meta-analysis-based nomogram. Oncologist 2015;20(10): 1111-1118

39 Iwase A, Nakamura T, Nakahara T, Goto M, Kikkawa F. AntiMüllerian hormone and assessment of ovarian reserve after ovarian toxic treatment: a systematic narrative review. Reprod Sci 2015;22(05):519-526 